\title{
Fall in skin temperature of exercising man
}

\author{
M. Torii MSc, M. Yamasaki PhD*, T. Sasaki MD ${ }^{\dagger}$ and H. Nakayama MD \\ Physical Fitness Laboratory, Kyushu Institute of Technology, Kitakyushu 804, Japan \\ *Department of Health and Physical Education, Faculty of Integrated Arts and Science, Hiroshima University, \\ Hiroshima 730, Japan \\ 'Department of Physiology, Ginkyo Junior College, Kumamoto 860, Japan \\ ‡Department of Hygiene, Tottori University School of Medicine, Yonago 683, Japan
}

\begin{abstract}
Fall in skin temperature during initial muscular work was investigated in ten healthy men. Bicycle exercise was performed at workloads of 50-150 $\mathrm{W}$ in a climatic chamber at ambient temperatures of $10-40^{\circ} \mathrm{C}$ (relative humidity 45-55\%). Skin temperatures at seven or eight points over the body surface were measured using thermography and thermocouple recording systems. Sweat rates were significantly higher at $40^{\circ} \mathrm{C}$ than at $30^{\circ} \mathrm{C}$, whereas the fall in skin temperature was almost equal. The reduction of skin temperature during exercise was the same throughout the year, although sweat rate was significantly higher in summer than in winter. In coloured thermographics of the skin temperature distribution during exercise of both $\mathbf{5 0}$ and $150 \mathrm{~W}$ at 10 or $20^{\circ} \mathrm{C}$, the skin temperature began to decline immediately at the onset of the exercise. Increased work intensities reduced skin temperature. The results suggest that fall in skin temperature during initial exercise was not due to increased evaporative cooling but to vasoconstriction, probably caused by non-thermal factors.
\end{abstract}

Keywords: Thermoregulation, thermographics, skin temperature, bicycle exercise

\section{Introduction}

Nielsen ${ }^{1}$ observed that the increase in core temperature of a muscular working man was proportional to workloads and, unlike mean skin temperature, largely independent of ambient temperature over the range $5-30^{\circ} \mathrm{C}$. Recently reduction in skin temperature has been detected during dynamic ${ }^{2-4}$ and static $^{5}$ muscular work. Dynamic exercise apparently causes skin temperature to fall as soon as exercise begins, although the mechanism is not yet fully understood. In the present study, skin temperature distribution of bicycling men was determined by thermography and thermocouple recording systems.

\section{Subjects and methods}

Three series of experiments were conducted in a climatic chamber at controlled temperatures of

Address for correspondence: Masafumi Torii, Physical Fitness Laboratory, Kyushu Institute of Technology, 1-1 Sensui-cho,

Kitakyushu 804, Fukuoka, Japan

(C) 1992 Butterworth-Heinemann Ltd

0306-3674/92/010029-04
Table 1. Characteristics of male volunteer exercise subjects

\begin{tabular}{lccccc}
\hline Experiment & Subject & $\begin{array}{c}\text { Age } \\
\text { (years) }\end{array}$ & $\begin{array}{c}\text { Height } \\
(\mathrm{cm})\end{array}$ & $\begin{array}{c}\text { Weight } \\
(\mathrm{kg})\end{array}$ & $\begin{array}{c}\dot{V}_{\mathbf{2}_{\text {max }}} \\
\left(\mathrm{I} \mathrm{min}^{-1}\right)^{*}\end{array}$ \\
\hline 1 & A & 28 & 165 & 63 & 2.90 \\
& B & 30 & 185 & 86 & 3.15 \\
& C & 28 & 166 & 68 & 2.70 \\
& D & 28 & 166 & 67 & 2.65 \\
& E & 29 & 165 & 62 & 2.85 \\
& F & 29 & 166 & 63 & 2.63 \\
& G & 22 & 167 & 55 & 2.85 \\
3 & H & 32 & 185 & 83 & 3.20 \\
& I & 30 & 165 & 66 & - \\
& J & 30 & 166 & 62 & - \\
\hline
\end{tabular}

* Maximal oxygen uptake $\left(\dot{V}_{\mathrm{O}_{2}}\right)$ determined from an incremental exercise test on a bicycle ergometer.

$10-40^{\circ} \mathrm{C}$. Subjects cycled at various work intensities. Age, height, weight and $\dot{V}_{\mathrm{O}_{2} \max }$ of the subjects are given in Table 1. $\dot{V}_{2} \max$ was determined by a modification of the technique of Miyamura and Honda $^{6}$. All subjects were untrained men who had not participated in regular physical conditioning for at least several years and had not been heat acclimated. They wore only underwear in the climatic chamber and each subject cycled at the same time of day to avoid variation due to circadian rhythm of body temperature 7 . Before the experiment the subjects rested for $30 \mathrm{~min}$ in a climatic chamber with controlled temperature. All experiments were carried out between 10.00 hours and 13.00 hours with the order randomized.

Values reported are mean(s.e.m.). Data were assessed by Student's $t$-test and one or two-way ANOVA. The level of significance was set at $P<0.05$.

\section{Experiments}

1. Skin temperature during moderate exercise in hot environments

Method

Subjects performed moderate bicycle exercise for 20 min and then sat on a bicycle ergometer. Ambient temperature $\left(T_{\mathrm{a}}\right)$ was controlled at 30 and $40^{\circ} \mathrm{C}$ with 
Fall in skin temperature during exercise: M. Torii et al.
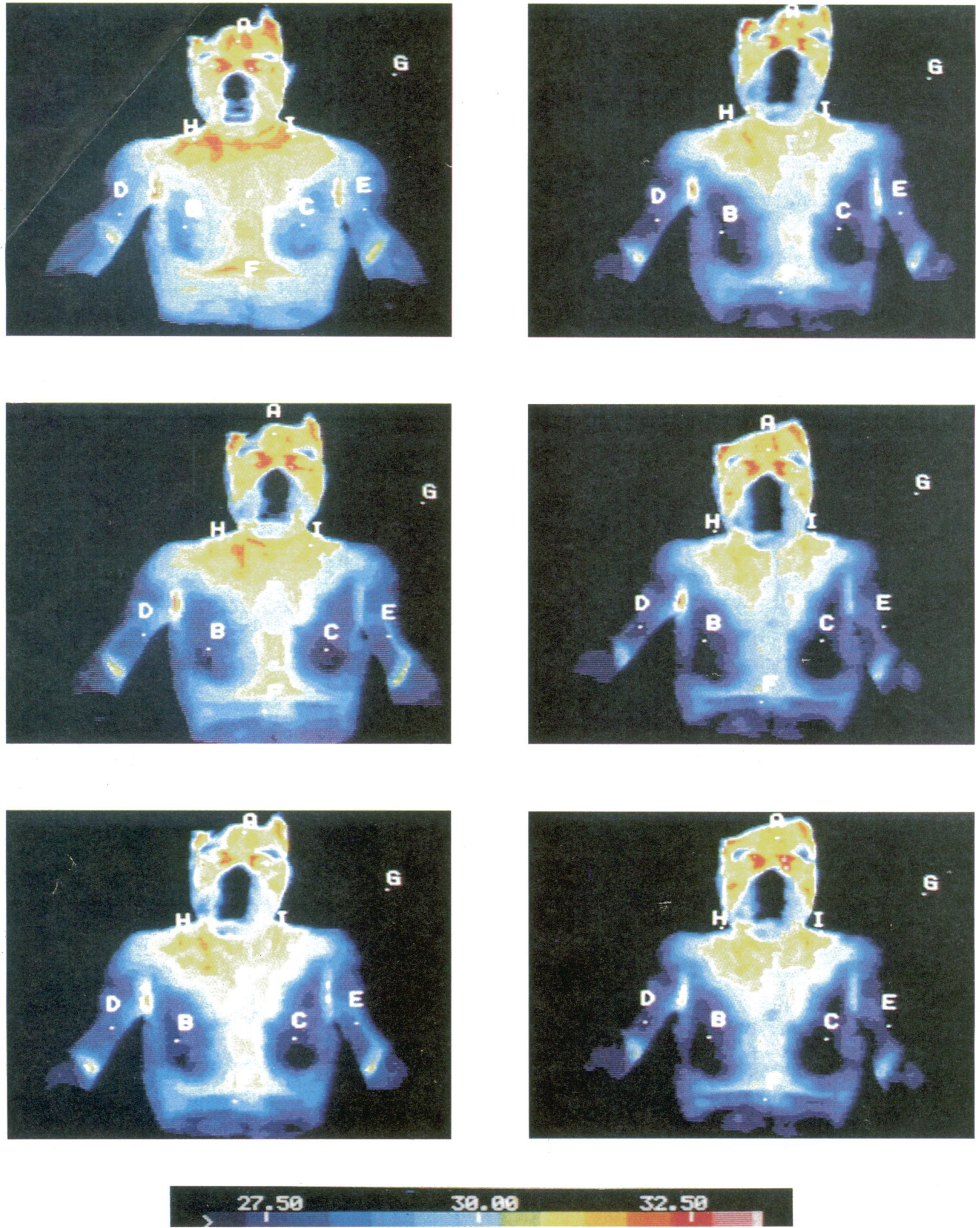

Figure 1. Thermographics of skin temperature data for subject $J$ at rest and during exercise at ambient temperature $\left(T_{\mathrm{a}}\right)$ of $10^{\circ} \mathrm{C}$. The location of eight skin temperature measuring points is indicated as $A-F, H$ and $I$ (G is wall temperature) on each plate. The plates are: a, before exercise; b, $1 \mathrm{~min} ; \mathrm{c}, 3 \mathrm{~min} ; \mathrm{d}, 5 \mathrm{~min} ; \mathrm{e}, 7 \mathrm{~min}$; and $\mathrm{f}, 9 \mathrm{~min}$ after the onset of exercise. Work intensity $50 \mathrm{~W}$. The temperature scale $\left({ }^{\circ} \mathrm{C}\right)$ is presented at the bottom. Blue zone, lower temperature; light blue and yellow zones, middle temperature; red zone, higher temperature 
Table 2. Fall in skin temperature and sweat rate (SR) of four men during exercise in hot environments

\begin{tabular}{lcll}
\hline Condition & $T_{\mathrm{a}}\left({ }^{\circ} \mathrm{C}\right)$ & $\Delta \bar{T}_{\text {sk }}\left({ }^{\circ} \mathrm{C}\right)$ & $\mathrm{SR}\left(\mathrm{g} \mathrm{min}^{-1}\right)$ \\
\hline Control & 30 & $-0.13(0.03)$ & $1.45(0.27)$ \\
Work & 30 & $-1.00(0.06)^{*}$ & $4.73(0.57)^{*}$ \\
Control & 40 & $-0.18(0.05)$ & $3.75(0.18) \dagger$ \\
Work & 40 & $-0.93(0.11)^{*}$ & $8.20(0.53)^{*}+$ \\
\hline
\end{tabular}

$T_{\mathrm{a}}$, ambient temperature; $\Delta \bar{T}_{\mathrm{sk}}$, decreasing mean skin temperature.

$P<0.05,{ }^{*}$ control versus work; $+30^{\circ} \mathrm{C}$ versus $40^{\circ} \mathrm{C}$, Student's

$t$-test.

Values of $\Delta \bar{T}_{\text {sk }}$ and SR are mean (s.e.m.)

relative humidity $45 \%$. The work intensity was $60 \mathrm{~W}$, $40 \%$ of maximal oxygen uptake $\left(\dot{V}_{2}\right.$ max $)$ in each subject.

Seven skin surface temperatures (forehead, arm, hand, foot, leg, thigh and trunk) were obtained every minute by a thermocouple recording system (AM300, Ohkura Electric, Japan). Mean skin temperature $\left(\bar{T}_{\text {sk }}\right)$ was calculated according to Hardy and DuBois ${ }^{8}$. Sweat rate was continuously monitored by an automatic weight loss indicator (bed balance, Model 33B, sensitivity $1.0 \mathrm{~g}$, J. A. Potter, Southington, Connecticut, USA) ${ }^{9,18}$.

\section{Results}

When subjects exercised under identical workloads, sweat rate was significantly higher at $40^{\circ} \mathrm{C}$ compared with $30^{\circ} \mathrm{C}$, but the decrease in $\bar{T}_{\text {sk }}$ was almost equal. The results are summarized in Table 2.

\section{Skin temperature during exercise in various seasons}

Method

Four healthy men bicycled at $60 \mathrm{~W}$ for $20 \mathrm{~min}$. $T_{\mathrm{a}}$ was controlled at $30^{\circ} \mathrm{C}$ and relative humidity was kept at $45 \%$. The experiments were repeated in the chamber

Table 3. Fall in skin temperature and sweat rate (SR) of four men during exercise in different seasons

\begin{tabular}{lccl}
\hline Season & $T_{\mathrm{a}}\left({ }^{\circ} \mathrm{C}\right)$ & $\Delta \bar{T}_{\mathrm{sk}}\left({ }^{\circ} \mathrm{C}\right)$ & $\mathrm{SR}\left(\mathrm{g} \mathrm{min}^{-1}\right)$ \\
\hline Winter & 30 & $-1.06(0.16)$ & $3.15(0.39)$ \\
Spring & 30 & $-1.16(0.21)$ & $4.23(0.20)$ \\
Summer & 30 & $-1.12(0.22)$ & $5.08(0.45)^{* *}$ \\
Autumn & 30 & $-1.01(0.10)$ & $4.30(0.17)$ \\
\hline
\end{tabular}

$T_{\mathrm{a},}$ ambient temperature; $\Delta \bar{T}_{\mathrm{sk}}$, decreasing mean skin temperature.

** $P<0.01$, significant difference from winter (student's $t$-test) Values of $\Delta \dot{T}_{\text {sk }}$ and $S R$ are mean (s.e.m.) in February, May, August and October under natural-seasonal acclimatization ${ }^{11} \cdot \bar{T}_{\text {sk }}$ and sweat rate were determined as described previously.

Results

A transient reduction in $\bar{T}_{\text {sk }}$ at an initial stage of the exercise was observed in winter, but in summer $\bar{T}_{\text {sk }}$ decreased gradually after the exercise started. There was a significant difference in sweat rate among subjects in various seasons $(P<0.01)$. However, the fall in $\bar{T}_{\text {sk }}$ was independent of seasons $(P>0.05$, mean(s.e.m.) $\left.1.08(0.14)^{\circ} \mathrm{C}, n=14\right)$ throughout the exercising period (Table 2).

In summer, as soon as the subjects started to exercise, sweating was observed for all experiments. In winter, it did not increase noticeably until after a few minutes. The mean sweat rate during exercise was significantly higher in summer than in winter (Table 3).

\section{Skin temperature of exercising man observed by colour thermography}

Method

Infra-red thermography ${ }^{12}$ makes it possible to visualize body surface temperature. Two healthy men volunteered as subjects. $T_{\mathrm{a}}$ was controlled at 10 or $20^{\circ} \mathrm{C}$ with relative humidity $55 \%$.

The work was perfomed on the bicycle ergometer at 50 and $150 \mathrm{~W}$. Eight skin surface temperatures on the upper half of the body (forehead, right and left upper arms, right and left chest, abdomen, and right and left neck parts) were observed by thermography (Thermoviewer JTG-500M system, Nihondenshi, Japan) before, during and after exercise. Temperature resolving power of the system was $0.2^{\circ} \mathrm{C}$. A polaroid camera was used to take a colour thermograph of 2-s scanning time at 1 -min intervals.

\section{Results}

Figure 1 shows selected colour thermography at rest $(a)$ and $1 \mathrm{~min}(b), 3 \mathrm{~min}(c), 5 \mathrm{~min}(d), 7 \mathrm{~min}(e)$ and $9 \mathrm{~min}(f)$ after the onset of exercise of light workload $(50 \mathrm{~W})$ at $10^{\circ} \mathrm{C}$. Skin temperatures began to fall immediately on starting to exercise. The chest and abdominal skin temperatures began to fall $3 \mathrm{~min}$ after the onset of exercise to $1.5-2.0^{\circ} \mathrm{C}$ at the end of exercise. After $7 \mathrm{~min}$ of exercise, the lowered temperature distribution spread to various body regions, especially the chest and upper arms. At $20^{\circ} \mathrm{C}$, skin temperature distribution during exercise was similar to that at $10^{\circ} \mathrm{C}$. At heavy work intensity $(150 \mathrm{~W})$ the forehead skin temperature fell by $3-6^{\circ} \mathrm{C}$. Increased work intensity produced a proportional reduction in skin temperature (Table 4).

Table 4. Two-way ANOVA table on fall in skin temperature to submaximal bicycle exercise

\begin{tabular}{lcccc}
\hline Source & Sum of squares & Degrees of freedom & Mean squares & $F>F$ \\
\hline Between $T_{\mathrm{a}}\left({ }^{\circ} \mathrm{C}\right)$ & 6.9038 & 1 & 6.9038 & 5.8355 \\
Between workload & 20.7253 & 1 & 0.258 \\
Interaction & 0.0012 & 1 & 0.0001 \\
Error & 70.9837 & 60 & 0.0012 & 1.183 \\
Total & 98.6140 & 63 & 0.973 \\
\hline
\end{tabular}




\section{Discussion}

The results obtained demonstrate a fall in skin surface temperature in the initial stage of dynamic exercise. In hot conditions, although there was a significant difference in sweating pattern in various seasons, the reduction of skin temperature was independent of the season. The reduction of skin temperature was approximately $1^{\circ} \mathrm{C}$ in these experiments. Skin sweating occurred earlier and became more profuse in the warm season than in the cold season, when subjects were exercising at the same environmental conditions, as pointed out by $\mathrm{Kuno}^{13}$. When subjects exercised at identical work intensity, sweating rate was significantly higher at an ambient temperature of $40^{\circ} \mathrm{C}$ than at $30^{\circ} \mathrm{C}$, but the decrease in skin temperature was almost equal. In a previous study, the reduction of skin temperature was found to be closely related to both non-thermal and thermal factors, such as the evaporative heat loss ${ }^{9,1} 0$.

Cutaneous vasoconstrictor response to exercise may explain the fall in finger blood flow and skin temperature following onset of leg exercise noted by Christensen and Nielsen ${ }^{14}$. Similarly, responses in forearm blood flow at intermittent 6-min period supine leg exercise were measured by plethysmography. There was a reduction in forearm blood flow of $37 \%$ at the initiation of the exercise $e^{15}$. Johnson et al. ${ }^{16}$ measured the forearm skin blood flow during leg work and suggested that increased blood flow was a result of competition between reflex vasoconstriction with muscular work and vasodilation due to increasing metabolic heat production. In addition, Nakayama et al. ${ }^{3,4}$ attributed the rise in core temperature during exercise to decreased heat loss due to persistently lower skin temperature. Then, skin temperature began to fall immediately at the onset of exercise. Increased workload produced a proportional reduction in skin temperature. They also suggested that the skin temperature during exercise was the result of competition between thermoregulatory vasodilation and reflex-induced vasoconstriction.

In summary, the present study suggests that fall in skin surface temperature is not related to the thermal factors, such as evaporation due to skin sweat.

\section{Acknowledgements}

This work was supported by a grant from the Meisen-kai, the Kyushu Institute of Technology Graduate's Association. The authors wish to thank Mr K. Ozaki, JEOL for his technical assistance.

\section{References}

1 Nielsen M. Die Regulation der Körpoertemperatur bei Muskelarbeit. Skand Arch Physiol 1938; 79: 193-230.

2 Clark RP, Mullan BJ, Pugh LGCE. Skin temperature during running - a study using infrared color thermography. I Physiol (Lond) 1977; 267: 53-62.

3 Nakayama T, Ohnuki Y, Niwa K. Fall in skin temperature during exercise. Ipn J Physiol 1977; 27: 423-37.

4 Nakayama T, Ohnuki Y, Kanosue K. Fall in skin temperature during exercise observed by thermography. Jpn J Physiol 1981; 31: 757-62.

5 Kashimura O, Ueda G. Thermographic observations of the skin related with the arm exercise. Jpn J Phys Fitness Sports Med 1986; 35: 83-92 (in Japanese).

6 Miyamura M, Honda Y. Oxygen intake and cardiac output during maximal treadmill and bicycle exercise. J App Physiol 1972; 32: 185-8.

7 Sasaki T. Circadian rhythm in body temperature. In: Itoh S, Ogata K, Yashimura H, (eds). Advances in Climatic Physiology. Tokyo: Igaku Shoin, 1972: 50-67.

8 Hardy JD, DuBois EF. The technique of measuring radiation and convection. J Nutr 1938; 15: 461-75.

9 Torii M, Yamasaki M, Sasaki T. Thermoregulatory response of the initial stage of bicycling in a heat environment. Jpn J Phys Fitness Sports Med 1984; 33: 98-104 (in Japanese).

10 Torii $M$, Yamasaki $M$, Sasaki T. Seasonal variation of sweating rate caused by exercise during thermal transient. J Human Ergol 1985; 14: 53-6.

11 Torii M, Yamasaki M, Sasaki T. Effects of heat stress on temperature regulation in initial exercise. J Hum Ergol 1986; 15: 3-12.

12 Barnes RB. Thermography of the human body: infraredradiant energy provides new concepts and instrumentation for medical diagnosis. Science 1963; 140: 870-7.

13 Kuno Y. Human Perspiration. Springfield: C. C. Thomas, 1956.

14 Christensen EH, Nielsen M. Investigations of the circulation in the skin at beginning of muscular work. Acta Physiol Scand 1942; 4: 162-70.

15 Johnson JM, Park MK. Effect of heat stress on cutaneous vascular responses to the initiation of exercise. J Appl Physiol Respirat Environ Exercise Physiol 1982; 53: 744-9.

16 Johnson JM, Rowell LB, Grengelmann GL. Modification of the skin blood flow-body temperature relationship by upright exercise. J Appl Physiol 1974; 37: 880-6. 